\title{
EFFECT OF HEAT TREATMENT ON THE PERIODIC CURRENT OSCILLATION OF POLYCRYSTALLINE ZINC IN ALKALINE SOLUTION
}

\section{J.J. PODESTÁ, R.C.V. PIATTI and A.J. ARVÍA}

Instituto de Investigaciones Fisicoquimicas Teóricas y Aplicadas (INIFTA), Casilla de Correo 16, Sucursal 4, 1900 La. Plata (Argentina)

(Received 6th December 1982)

The phenomenology of the periodic oscillations of the faradaic current of zinc electrodes in alkaline solutions [1-4] offers the possibility of investigating the influence of the non-uniformity of the polycrystalline metal surface on the periodic effect because the grain size of zinc can be easily controlled by the annealing temperature and time. Zinc rods $(0.6 \mathrm{~cm}$ dia., Leico $99.999 \%$ purity) were annealed at $390^{\circ} \mathrm{C}$ during a period of between 2 and $6 \mathrm{~h}$ and cooled down for about $18 \mathrm{~h}$. Each annealed rod was axially embedded in a PTFE rod to make a still zinc disc working electrode in contact with $1.5 \mathrm{M} \mathrm{NaOH}$ at $25^{\circ} \mathrm{C}$. Other experimental details are as described in a previous publication [4]. The morphology of the attack of the different electrode surfaces is shown in Fig. 1. From these pictures the surface density of grains at the electrode was calculated.

The potential applied to each electrode to produce the periodic current oscillations is $-1.09 \mathrm{~V}$ (vs. $\mathrm{Hg} / \mathrm{HgO} / 1 \mathrm{M} \mathrm{NaOH}$ ). The period of the oscillating current decreases linearly according to the surface density of grains (Fig. 2). At a fixed potential the current oscillation period is, in principle, independent of the radius $r$ of the disc electrode for $0.1 \leqslant r \leqslant 0.3 \mathrm{~cm}$. Within this range, it appears that no edge effect contributes appreciably to the oscillation phenomena.

Furthermore, the oscillation period remains unaltered after a surface scratching with a diamond tip. The activation portion of each oscillating current is practically the same for the different zinc electrodes including the corresponding charge and peak current. These results correspond to a fast electrodissolution process, in agreement with previously reported kinetic data [5-7]. Conversely, the passivation region of each oscillating period increases considerably as the surface density of grains decreases. The passivation region is related to the precipitation of $\mathrm{Zn}(\mathrm{OH})_{2}$ [4]. These results, including those shown in Fig. 1, are in harmony with the explanation of the periodic phenomena given in previous publications related to other electrode systems [8-11], based on a time-varying area of the active and passive regions. At the initiation of the passive region the metal electrodissolution and the growth of the passive film are appreciably decreased, so that no fresh metal surface is available. Under these conditions, the time required for the film to dissolve depends on the dislocation density at the metal surface, namely the change in texture 


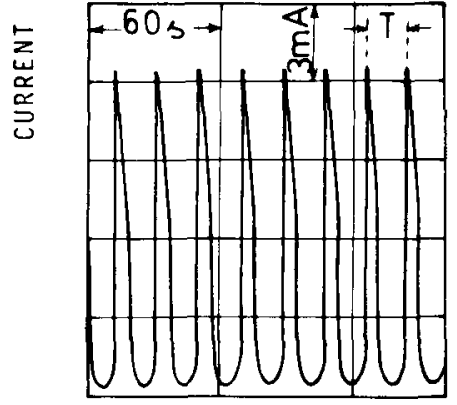

TIME
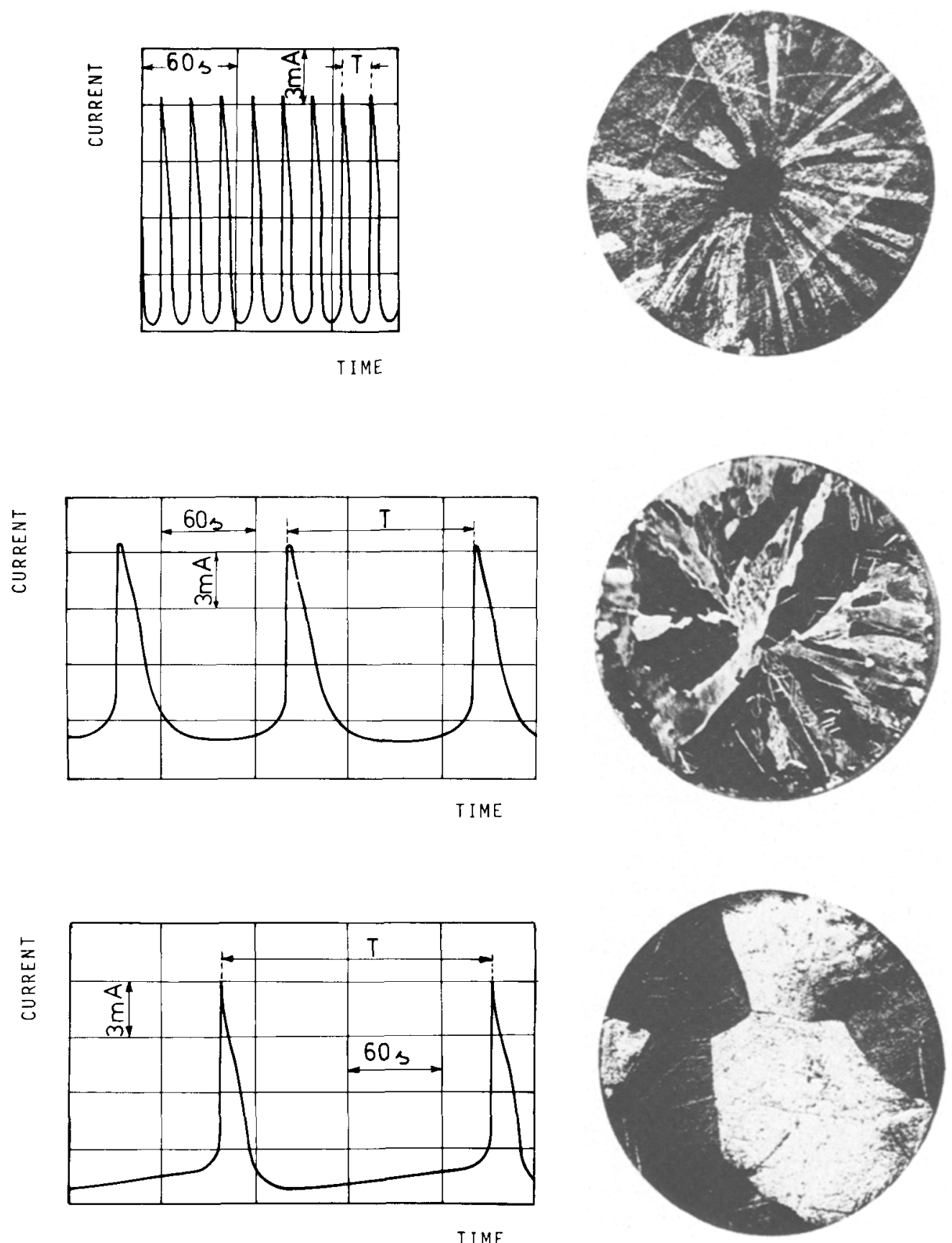

Fig. 1. Morphology of attack of $\mathrm{Zn}$ electrodes and the characteristics of the corresponding oscillating current at $E=-1.09 \mathrm{~V}$, in $1.5 \mathrm{M} \mathrm{NaOH}$ at $25^{\circ} \mathrm{C}$. Density of grains: $1.33,0.55$ and 0.16 grains $\mathrm{cm}^{-2}$. 


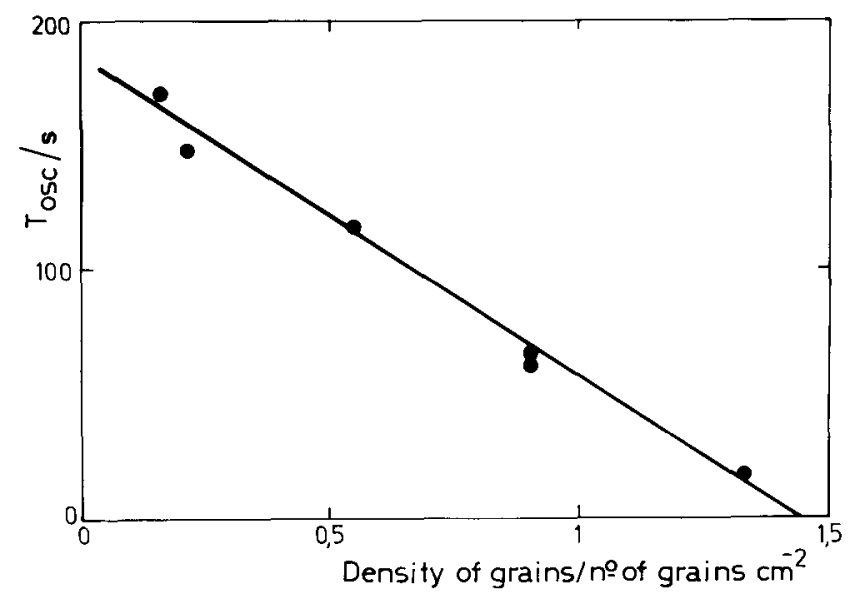

Fig. 2. Dependence of the oscillating current period on the density of grains of the Zn electrode; $1.5 M$ $\mathrm{NaOH}, 25^{\circ} \mathrm{C}$.

of the zinc surface, as the grain boundaries can be related to the constraints defining the active/passive regions at the electrode. As the electrodissolution process should start at the grain boundaries, the greater the time required to attain the active to passive area ratio associated with the sudden electrodissolution of the metal, the smaller the dislocation density, i.e. the smaller the extension of the grain boundaries.

The influence of the zinc texture in the characteristics of the periodic current oscillation under a constant applied potential correlates with the effect of crystal-grain size on the adsorption properties of polycrystalline zinc for cyclohexanol in $0.1 \mathrm{M}$ $\mathrm{KCl}$ at $\mathrm{pH} 3.7$ [12]. The corresponding results have shown that the adsorption energy of water on $\mathrm{Zn}$ increases due to a high dislocation density and greater extension of the grain boundaries where water is adsorbed preferentially. Consequently, the pzc of the non-annealed zinc electrode is slightly more negative $(\sim 20$ $\mathrm{mV}$ ) than that of the annealed electrode.

In conclusion, the energetic non-uniformity of the polycrystalline zinc surface plays an important role in determining the characteristics of both periodic phenomena and adsorption properties.

\section{REFERENCES}

1 U.F. Franck, Z. Elektrochem, Ber. Bunsenges. Phys. Chem., 62 (1958) 649.

2 M.N. Hull, J.E. Ellison and J.E. Toni, J. Electrochem. Soc., 117 (1970) 192.

3 M.N. Hull and J.E. Toni, Trans. Faraday Soc., 67 (1971) 1128.

4 R.C.V. Piatti, J.J. Podestá and A.J. Arvía, Electrochim. Acta, 25 (1980) 827.

5 R.J. Brodd and V.E. Leger in A.J. Bard (Ed.), Encyclopedia of Electrochemistry of the Elements, Vol. V, Marcel Dekker, New York, 1976, p. 35. 
6 J. McBreen and E.J. Cairns in H. Gerischer and C.W. Tobias (Eds.), Advances in Electrochemical Engineering, Vol. 11, Wiley-Interscience, New York, 1978, p. 298.

7 V.S. Muralidharan and K.S. Rajagopalan, J. Electroanal. Chem., 94 (1978) 21.

8 J.J. Podestá, R.C.V. Piatti and A.J. Arvía, J. Electrochem. Soc., 126 (1979) 1363.

9 J.J. Podestá, R.C.V. Piatti and A.J. Arvia, Electrochim. Acta, 24 (1979) 633.

10 J.J. Podestá, R.C.V. Piatti and A.J. Arvía, Corros. Sci., 22 (1982) 193.

11 J.J. Podestá, R.C.V. Piatti and A.J. Arvía. Corrosion, 38 (1982) 599.

12 A.I. Danilov, V.V. Batrakov and V.A. Safonov. Sov. Electrochem. 16 (1980) 90. 